\title{
Differences in the Level of Morphological Characteristics, Speed Abilities and Aerobic Endurance in Relation to the Team Position of Top Female Football Players
}

\author{
Izet Bajramovic', Slavenko Likic ${ }^{1}$, Munir Talovic ${ }^{1}$, Haris Alic ${ }^{1}$, Eldin Jeleskovic', Goran Sporis ${ }^{2}$ \\ 'University of Sarajevo, Faculty for Sport and Physical Education, Bosnia and Herzegovina, ${ }^{2}$ University of Zagreb, Faculty of Kinesiology, Croatia
}

\begin{abstract}
The aim of this paper is to determine the differences in the level of morphological characteristics, speed abilities and aerobic endurance according to the team positions of top female football players. The study included 18 female football players (age 21.33 \pm 3.67 , body mass index 20.94 \pm 1.95 ). Female football players are classified under the following team positions: defenders ( $n=7 ; 23 \pm 16.4$ years), midfielders $(n=6,20.5 \pm 14.3$ years) and attackers ( $n=5 ; 20 \pm 31.3$ years). The following tests were used: $0-5 m$ sprint (s), $0-10 \mathrm{~m}$ sprint (s), 0-20m sprint (s), 0-30m sprint (s) and Beep test. Body mass index (BMI) was calculated based on the ratio of body weight $(\mathrm{kg})$ and body height $(\mathrm{cm})$. Based on the Beep test, the maximum oxygen consumption $\left(\mathrm{VO}_{2 \max }\right)$ was calculated and presented in its relative value $(\mathrm{ml} / \mathrm{kg} / \mathrm{min})$. The attackers had a higher body height $(170.1 \pm 7.46)$ and weight $(59.60 \pm 8.84)$ than those playing in midfield and defense positions. Also, the attackers were faster in the sprint on the $5 \mathrm{~m}(1.17 \pm .06), 10 \mathrm{~m}(1.91 \pm .06), 20 \mathrm{~m}(3.27 \pm .10)$ and $30 \mathrm{~m}(4.51 \pm .17)$ than female players in midfield and defense positions. Midfield players had higher level of $\mathrm{VO}_{2 \max }(50.03 \pm 2.69)$ than female players in defensive and offensive team positions. Test results of univariate analysis of variance (ANOVA) showed that there are significant differences in the level of morphological features, speed and aerobic endurance capabilities between the top female football players, regardless of their team position ( $p>0.05$ ). It is obvious that good speed abilities on short sprint sections as well as high level of aerobic endurance at high intensity are required regardless of players team position in the women's football. It is important to note that selection for team positions can not only be based on morphological characteristics, speed abilities and aerobic endurance of players. Also, tactical tasks as well as technical characteristics of players need to be considered for selection of team positions in the women's football.
\end{abstract}

Key words: Women's Top Football, Differences in Team Positions, Defenders, Midfielders, Attackers

\section{Uvod}

Nogomet je timska sportska igra koja pred igrače postavlja niz, tehničko-taktičkih i kondicionih zahtjeva. Istraživanja na fudbalerkama su znatno rijeđa u odnosu na fudbalere, ali čini se da igra postavlja slične zahtjeve (Todd, Scott i Chisnall, 2002). Ipak, postoje značajne razlike po spolovima u profesionalnom fudbalu, a koje su više izražene u aerobnoj izdržljivosti nego u anaerobnom režimu rada (Mujika i sar., 2009). Takođe, profesionalne igračice fudbala imaju impresivnu mišićno zdravstvenu sliku u uporedbi sa neaktivnim ženama (Jackman i sar., 2013).

Naime, u svakom sportu i sportskoj disciplini postoje specifičnosti i različitosti u takmičarskoj strukturi, što je nametnulo potrebu za neprekidnim istraživanjem i potvrđiva-

Correspondence:

Montenegro S.Likić

Gport University of Sarajevo, Faculty for Sport and Physical Education, Patriotske lige 41, 71000 Sarajevo, Bosnia and Herzegovina E-mail: slavenkolikic@gmail.com 
njem u praksi upravo takvih specifičnosti (Vukotić, Ćorluka, Vasiljević i Bubanja, 2018). Svakako da istraživanja koja obuhvataju fudbalsko-specifične komponente, treba koristiti radi šireg razumijevanja i procjene kvalitete igračica i njihovog mogućeg doprinosa timu.

Pored potrebe za velikom izdržljivošću rada pri velikom intenzitetu i intermitentnom režimu naprezanja, konkretno ženski fudbal spada u kategoriju sportova uz prisusutvo kretanja velikom brzinom (Bjelica, 2006). Naime, najbrži oblik prirodnog kretanja sportiste je sprintanje, te predstavlja jedan od najvažnijih kvaliteta brzine u mnogim sportovima (Bajramovic, Likic, Manic \& Mekic). Profesionalne fudbalerke postižu brzinu u rasponu $22-26 \mathrm{~km} / \mathrm{h}$ na udaljenosti od $15-20 \mathrm{~m}$, a mogu dostići i $27 \mathrm{~km} / \mathrm{h}$ pri sprintevima preko 35m (Vescovi, 2012a). Da bi igračice bile sposobne ostvariti ovakve zahtjeve tokom igre, od njih se zahtjevaju apsolutno najveći domeni u fizičkoj pripremljenosti.

Najbrže igračice vjerovatno bolje primjenjuju svoje tehničke i druge sposobnosti u igri, u odnosu na sporije igračice sa sličnim vještinama. Vjerovatno da kvalitet igre u odbrambenim akcijama raste u slučaju poboljšanja brzinsko-snažnog potencijala. Vescovi (2012b) je utvrdio razlike u brzinskim sposobnostima tipa sprinta između prvotimki i rezervnih igračica. Najvjerovatnije da brže fudbalerke imaju prioritet pri određivanju startne postave tima. Poznato je da određene morfološke karakteristike i kondicione performanse mogu imati prednost pri realizaciji specifičnih zadataka na različitim timskim pozicijama tokom igre. Tako naprimjer, više igračice mogu imati prednost $u$ vazdušnim duelima $u$ odnosu na niže igračice. Naime, morfološke karakteristike su važne za izbor timske pozicije, što se posebno odnosi na golmane (Sporiš, Čanaki \& Barišić, 2007a).

Težnja za takmičenjima na međunarodnom nivou je vjerovatno veliki izazov za fudbalerke. Ipak, broj realiziranih sprintova visokog intenziteta tokom fudbalske utakmice, predstavlja glavni faktor koji diskriminira igračice međunarodnog i nacionalnog nivoa takmičenjima (Gabbett, 2010; Andersson, Randers, Heiner-Møller, Krustrup \& Mohr 2010a). Naime, vrhunske igračice međunarodnog nivoa izvode više intenzivnih intervala trčanja tokom utakmice, u odnosu na igračice nižeg nivoa takmičenja.

Sa druge strane, kada su u pitanju timske pozicije, zapažanja ukazuju da središnje igračice pokrivaju veću ukupnu udaljenost tokom utakmice $(10,67 \pm 1,34 \mathrm{~km})$, u odnosu na odbrambene $(9,62 \pm 1,20 \mathrm{~km})$ i napadačke timske pozicije $(9,61 \pm 0,36 \mathrm{~km})$, dok napadačice realizuju više sprinteva bržih od $25 \mathrm{~km} / \mathrm{h}(0,52 \pm 0,03 \mathrm{~km})$ u odnosu na središnje $(0,43 \pm 0,04 \mathrm{~km})$ i odbrambene igračice $(0,33 \pm 0,05 \mathrm{~km})$ (Datson, Hulton, Andersson, Lewis, Weston, Drust, Gregson 2014a). Naime, aerobni kapacitet je važna odrednica broja intenzivnih akcija koje izvode vrhunske igračice u igri (Krustrup, Mohr, Ellingsgaard i Bangsbo, 2005a). Evidentno je da permanentno praćenje stanja treniranosti igračica i analize pozicionih zahtjeva, trenerima omogućuje konkretniji uvid sa ciljem oblikovanja trenažnog procesa i realizacije periodičnih ciljeva treninga u ženskom profesionalnom fudbalu.

$\mathrm{Na}$ osnovu dosadašnjih saznanja i specifičnih zahtjeva koji su vezani za timske pozicije u igri, može značiti da bi se fudbalerke trebale odlikovati odgovarajućim morfološkim karakteristikama i funkcionalnim brzinskim kvalitetima tipa sprinta. Cilj ovog rada je utvrditi razlike u nivoima morfoloških karakteristika, brzinskih sposbnosti i aerobne izdr- žljivosti u odnosu na timske pozicije u ženskom vrhunskom fudbalu.

\section{Metod}

U istraživanju je učestvovalo 18 namjerno odabranih vrhunskih fudbalerki (starosne dobi 20.72 \pm 3.66 ). Ispitanice su članice aktuelnog prvaka Bosne i Hercegovine, odnosno kluba koji se takmiči u najelitnijem međunarodnom takmičenju za žene. Ispitanice su takođe stalne ili povremene reprezentativke A-nacionalnog tima Bosne i Hercegovine.

Testiranje je obavljeno neposredno pred početak drugog dijela fudbalske sezone. Uslov za testiranje je bilo optimalno psihofizičko zdravlje, minimalno petogodišnji trenažni i igrački staž, minimalno $70 \%$ odigranih utakmica u aktuelnoj sezoni takmičenja. Ispitanice su prije testiranja upoznate sa principima Helsinške deklaracije, te su dobrovoljno pristale na testiranje uz mogućnost odustajanja u bilo kojem trenutku.

Testiranje je obavljeno na vještačkoj podlozi, na temperaturi od $21^{\circ} \mathrm{C}$. Testiranju je prethodilo standardizovano zagrijavanje (jogging 5 minuta, dinamičko/statičko istezanje 7 minuta i istrčavanja sa postepenim akceleracijama brzine do 90\% 3 minuta). U vremenskom periodu od 48 sati prije testiranja, ispitanice su bile dužne izbjegavati visokointenzivne treninge.

$\mathrm{Na}$ osnovu izjave trenera, igračice su klasifikovane kao odbrambene ( $\mathrm{n}=7$; starosna dob $23 \pm 4.16)$, srednjeg reda $(\mathrm{n}=6$; starosna dob $20.5 \pm 3.14)$ i napadačice $(\mathrm{n}=5$; starosna

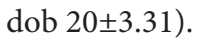

Uslov za navedenu raspodjelu je bilo minimalno $70 \%$ odigranih utakmica na jednoj od navedenih timskih pozicija tokom prethodne polusezone. Obzirom na specifičnu ulogu $\mathrm{u}$ timu, golmanice se nisu uzele u razmatranje za ovo istraživanje. BMI se izračunao na osnovu odnosa vrijednosti tjelesne težine $(\mathrm{kg})$ i kvadrata tjelesne visine $(\mathrm{cm})$. Za procjenu brzinskih sposobnosti tipa sprinta se koristio Micro-gateov sistem za mjerenje vremena putem fotoćelija (Micro-gate Photocell, Bolzano, Italy), a izmjereno je vrijeme na dionicama: $0-5 \mathrm{~m}$ sprint (s), $0-10 \mathrm{~m}$ sprint (s), 0-20m sprint (s); te vrijeme za procjenu brzine sprintanja $0-30 \mathrm{~m}$ sprint (s). Za procjenu aerobne izdržljivosti korišten je Beep test, na osnovu kojeg se izračunala vrijednost maksimalne kiseoničke potrošnje $\left(\mathrm{VO}_{2 \max }\right)$ izražena putem vrijednosti relativnog odnosa $(\mathrm{ml} / \mathrm{kg} / \mathrm{min})$ prema formuli: VO2max $(\mathrm{ml} / \mathrm{kg} / \mathrm{min})$ $=18.043461+(0.3689295 \times$ TS $)+(-0.000349 \times$ TS $x$ TS $)$, gdje TS predstavlja ukupan broj intervala (Legel \& Gadoury, 1989).

Prikazane su srednje vrijednosti rezultata i standardna devijacija $( \pm)$. Utvrđivanje razlika između timskih pozicija $u$ igri su provedene pomoću testa univarijatne analize varijanse (ANOVA). Statistički značaj je prihvaćen na nivou $\mathrm{p} \leq 0,05$.

\section{Rezultati}

Uvidom u srednje vrijednosti rezultata istraživanja, prikazanih u tabeli 1 , evidentno je da su igračice napada nešto više i teže u odnosu na igračice koje igraju na pozicijama odbrane i sredine terena. Igračice napada su ostvarile najbolje prosječno vrijeme u svim testovima za procjenu brzinskih sposobnosti tipa sprinta, dok su igračice odbrane bile brže od igračica koje igraju na poziciji sredine terena. Središnje igračice su ostvarile najbolju prosječnu vrijednost nivoa $\mathrm{VO}_{2 \max }$ $(\mathrm{ml} / \mathrm{kg} / \mathrm{min})$. 
Tabela 1. Mjere centralne tendencije i disperzije morfoloških karakteristika, brzinskih sposobnosti i aerobne izdržljivosti u odnosu na timsku poziciju vrhunskih fudbalerki

\begin{tabular}{lcccc}
\hline & $\begin{array}{c}\text { Odbrambeni } \\
\mathbf{N = 7}\end{array}$ & $\begin{array}{c}\text { Vezni } \\
\mathbf{N = 6}\end{array}$ & $\begin{array}{c}\text { Napadači } \\
\mathbf{N = 5}\end{array}$ & $\begin{array}{c}\text { Total } \\
\mathbf{N = 1 8}\end{array}$ \\
\hline Visina tijela & $165.6 \pm 4.54$ & $166.8 \pm 5.30$ & $170.1 \pm 7.46$ & $167.1 \pm 5.94$ \\
Težina tijela & $55.42 \pm 4.57$ & $57.16 \pm 6.17$ & $59.60 \pm 8.84$ & $57.16 \pm 6.32$ \\
BMI & $20.59 \pm .2 .17$ & $21.58 \pm 2.10$ & $20.66 \pm .1 .58$ & $20.94 \pm 1.95$ \\
0-5m sprint (s) & $1.18 \pm .06$ & $1.20 \pm .05$ & $1.17 \pm .06$ & $1.19 \pm .05$ \\
0-10m sprint (s) & $1.93 \pm .05$ & $1.95 \pm .08$ & $1.91 \pm .06$ & $1.93 \pm .06$ \\
0-20m sprint (s) & $3.30 \pm .07$ & $3.38 \pm .10$ & $3.27 \pm .10$ & $3.32 \pm .09$ \\
0-30m sprint (s) & $4.61 \pm .21$ & $4.63 \pm .15$ & $4.51 \pm .17$ & $4.65 \pm .17$ \\
$\mathrm{VO}_{2 \text { max }}$ (ml/kg/min) & $48.06 \pm 1.18$ & $50.03 \pm 2.69$ & $48.60 \pm 3.05$ & $48.89 \pm 2.31$ \\
\hline
\end{tabular}

Rezultati testa univarijatne analize varijanse (ANOVA) su ukazali da ne postoje statistički značajne razlike $(\mathrm{p}>0.05)$ u nivoima morfoloških karakteristika, brzinskih sposobnosti i aerobne izdržljivosti u odnosu na njihovu dominantnu timsku ulogu vrhunskih fudbalerki (tabela 2).

Tabela 2. Razlike u nivoima morfoloških karakteristika, brzinskih sposobnosti i aerobne izdržljivosti u odnosu na timsku poziciju vrhunskih fudbalerki

\begin{tabular}{cccccc}
\hline & $\begin{array}{c}\text { Sum of } \\
\text { Squares }\end{array}$ & df & Mean Square & F & Sig. \\
\hline Visina tijela & 113.59 & 2 & 56.79 & 1.748 & .208 \\
Težina tijela & 50.75 & 2 & 25.37 & .604 & .559 \\
Body mas index & 2.32 & 2 & 1.16 & 1.18 & .333 \\
0-5m sprint (s) & .003 & 2 & .002 & .516 & .607 \\
$0-10 \mathrm{~m}$ sprint (s) & .002 & 2 & .001 & .233 & .795 \\
$0-20 \mathrm{~m}$ sprint (s) & .032 & 2 & .016 & 2.018 & .167 \\
$0-30 \mathrm{~m} \mathrm{sprint}(\mathrm{s})$ & .051 & 2 & .026 & .843 & .405 \\
$\mathrm{VO}_{2 \text { max }}(\mathrm{ml} / \mathrm{kg} / \mathrm{min})$ & 11.89 & 2 & 5.94 & 1.085 & .363 \\
\hline
\end{tabular}

\section{Diskusija}

Dobiveni rezultati se podudaraju sa prethodnim studijama na uzorku žena (Krustrup i sar 2005b; Sporiš i sar., 2007b; Alexiou i Coutts, 2008; Ingebrigtsen i sar., 2011; Milanović, Sporiš i Trajković, 2012; Haugen, Tønnessen, Hem, Leirstein i Seiler, 2014; Trajković, Sporiš, Milanović i Jovanović, 2014; Nikolaidis, 2014; Datson, Hulton, Andersson, Lewis, Weston, Drust i Gregson, 2014b).

Poznato je da u slučaju centralnih igrača (igrača odbrane i napada) dominira tjelesna visina, koja u slučaju veznih i bočnih nije toliko presudna (Bjelica, Gardasević i Vasiljević, 2018). Ipak treba naglasiti, da su u ovom istraživanju igračice svrstane u odnosu na zadnju ili odbrambenu liniju, srednju ili veznu i prednju ili napadačku, za razliku od mogućnosti razvrstavanja prema položaju u polju: centralni stoperi, bočni bekovi, centralni vezni, vanjski napadači i centralni napadači. Takvo razvrstavanje je moglo doprinijeti dobivenim drugačijim srednjim vrijednostima rezultata.

Suštinski gledano, priroda nogometne igre zahtijeva od svih igračica brzu realizaciju fudbalskih akcija sa i bez lopte, što se posebno odnosi na napadačice. Za napadačke zadatke je sposobnost kratkog sprinta od velikog značaja, s obzirom na stalnu potrebu kreiranja prostora za sebe i saigrače te ciljem efikasne završnice. U nogometnoj igri je prisutna permanentna interakcija napadačica jedne ekipe i odbrambenih igračica druge ekipe. U navedenoj situaciji prve imaju zadatak da nadigraju odbrambene, dok druge imaju zadatak da spriječe igračice napada, što ukazuje na velike mogućnosti pri oblikovanju sličnog trenažnog programa. Bolje vrijednosti $\mathrm{VO}_{2 \max }(\mathrm{ml} / \mathrm{kg} / \mathrm{min})$ u slučaju sre- dišnjih igračica su vjerovatno izražene zbog učestalih kretanja po dubini i širini terena tokom igre, te stalnom vezom između odbrane i napada. Ipak, kako bi se zadovoljili izazovi međunarodnih fudbalskih utakmica, sposobnost obavljanja intenzivnih aktivnosti bi se trebala redovno trenirati sa elitnim fudbalerkama (Andersson i sar. 2010b)

Kao timska sportska igra, nogomet pred igračice postavlja niz zahtjeva, koji pripadaju cjelokupnom antropološkom prostoru. Očigledno je da su brzinske sposbnosti tipa sprinta i visoki nivo aerobne izdržljivosti u uslovima visokog intenziteta rada potrebni za svaku timsku poziciju u igri. Važne pretpostavke za postizanje brzine kretanja su: visoka aktivnost nervno-mišićnog sistema, elastična snaga i gipkost, sposobnost opuštanja mišića, kvalitet sportske tehnike, biohemijski procesi, energetske zalihe u mišićima i tempo iskorištavanja energetskih supstanci (Bjelica i Fratrić, 2011).

Igračice tokom fudbalske igre vrše prelaz iz odbrane $u$ napad i obratno, te se ovakve aktivnosti konstantno ponavljaju. Zbog toga bi aerobni trening visokog intenziteta i trening brzine trebali imati visoki prioritet, te bi se trening ciljano trebao usmjeravati na poboljšanje ovih kvaliteta (Magni, Krustrup, Andersson, Kirkendal i Bangsbo, 2008; Manson, Brughelli i Harris 2014). Poznata je pozitivna korelacija između maksimalne potrošnje kisika i visokog intenziteta trčanja tokom igre (Krustrup i sar. 2005c), što dodatno sugeriše na permanentni razvoj nivoa funkcionalnih sposobnosti, koje mogu biti od velike važnosti za kvalitetu fudbalske igre. Niže vrijednosti BMI-a, postotka tjelesne masti i masno tkivo u značajnoj mjeri utječu na vrijednosti parametara brzine (Covic, Causevic, Jeleskovic, Alic, Talovic i 
Radjo, 2017; Likic, Bajramovic \& Vranesic-Hadzimehmedovic, 2018). Postizanje optimalnog BMI-a može rezultirati poboljšanjima u pogledu općeg nivoa tjelesne i nivoa anaerobne snage, a samim tim i poboljšanju performansi (Nikolaidis, 2014). Corluka, Bjelica, Vasiljevic, Bubanja, Georgiev i Zeljko (2018) ukazuju na način koji omogućuje optimizaciju parametara morfoloških svojstava i sastav tijela. Pored toga, pliometrijski trening može biti koristan za poboljšanje sprinterskih i skakačkih sposobnosti fudbalerki, što se posebno odnosi na takmičarski period sezone tokom kojeg nema puno raspoloživog vremena za dodatne treninge (Ozbar, Ates \& Agopyan, 2014).

Ipak, taktički zadaci u odnosu na timsku poziciju i individualne kretne aktivnosti se trebaju uzeti u obzir s ciljem oblikovanja trenažnog programa. S druge strane, posjedovanje tačne tehničke analize i preciznih igračkih zahtjeva na svakoj poziciji bi omogućilo uspostavljanje tačnijeg igračkog profila (Talovic, Fiorentini, Sporis, Jeleskovic, Ujevic i Jovanovic, 2011). Rezultati ovog istraživanja imaju svrhu orijentacije i izbora igrača, kao i praćenja efekata treninga. Ipak, pored važnosti navedenoga, odabir za timsku poziciju ne može se bazirati samo na osnovu morfoloških karakteristika, aerobnog kapaciteta ili brzinskih sposobnosti igračica fudbala. Takođe, rezultat igre ne procjenjuje se na razini motoričke izvedbe u smislu njene količine i brzine, nego prema broju ostvarenih ciljeva (Bjelica, Milosevic, Talovic \& Bajramovic, 2018).

Jasno je da bi se u budućim istraživanjima trebala obuhvatiti cjelovitija analiza i drugih aspekata fudbalske igre, kako bi se dobilo još više informacija, kojima bi se eventualno mogli konkretnije utvrditi profili na specifičnim timskim pozicijama. Dozirano učešće elementarnih biomotoričkih dimenzija u raznim sportskim disciplinama, dozirana potrošnja energetskih potencijala u toku trajanja raznih sportskih disciplina, kao i specifičan oblik izvođenja sportske discipline, jednostavno nameću sportskim stručnjacima obavezu da za svaku sportsku disciplinu odrede principe izbora sredstava sportskog treninga (Bjelica, 2005). Takođe, u istraživačkoj i trenažnoj praksi je potrebno neprestano težiti konstruisanju novih mjernih instrumenata, kojim bi se eventualno mogao pružiti validniji uvid u tretiranu problematiku. Svakako da se sociološke, psihološke i posebno fudbalsko-specifične komponente trebaju koristiti zbog šireg razumijevanja i procjene kvaliteta igračica fudbala, kako bi se bolje definisao njihov potencijalni doprinos uspjehu tima.

\section{Acknowledgements}

There are no acknowledgements.

\section{Conflict of Interest}

The authors declare that there are no conflict of interest.

Received: 16 April 2018 | Accepted: 11 June 2018 | Published: 13 July 2018

\section{References}

Alexiou, H., Coutts A. (2008). A Comparison of Methods Used for Quantifying Internal Training Load in Women Soccer Players. International Journal of Sports Physiology and Performance, 3(3), 320-30.

Andersson, $\mathrm{HA}$, Randers, MB, Heiner-Møller, A, Krustrup, P, and Mohr, M. (2010). Elite female soccer players perform more high-intensity running when playing in international games compared with domestic league games. J Strength Cond Res 24(4), 912-9.

Bajramovic, I., Likic, S., Manic, G. \& Mekic, A. (2015). Dizajniranje savremenog kondicionog treninga. Sarajevo: Fakultet sporta i tjelesnog odgoja.

Bjelica, D. (2005). Sistematizacija sportskih disciplina i sportski trening. Podgorica: Crnogorska sportska

akademija.

Bjelica, D. (2006). Sportski trening. Podgorica: Crnogorska sportska akademija. Bjelica, D., \& Fratrić, F. (2011). Sportski trening: teorija, metodika i dijagnostika.
Nikšić: Fakultet za sport i fizičko vaspitanje.

Bjelica, D., Gardasević, J., Vasiljević, I. (2018). Differences in the Morphological Characteristics and Body Composition of Football Players FC Sutjeska and FC Mladost in Montenegro. J. Anthr. Sport Phys. Educ. 2(2) 31-5.

Bjelica, D., Milosevic, Z., Talovic, M., Bajramovic, I. (2018). Repulsion of the Futsal Ball Depending on the Pressure in it. Sport Mont, 16(2), 61-7.

Corluka, M., Bjelica, D., Vasiljevic, I., Bubanja, M., Georgiev, G., Zeljko, I. (2018). Morphological Characteristics and Body Composition of Football Players of HSC Zrinjski Mostar and FC Siroki Brijeg in Bosnia and Herzegovina. Sport Mont, 16(2), 77-81.

Čović, N., Čaušević, D., Jelešković, E., Alić, H., Talović, M. \& Rađo, I. (2017). Kompozicija tijela kao indikator brzinskih sposobnosti mladih nogometaša. In Proceedings 15. godišnja međunarodna konferencija kondicijska priprema sportaša 2017 (86-90). Zagreb: Udruga kondicijskih trenera Hrvatske.

Datson, N., Hulton, A., Andersson, H., Lewis, T., Weston, M., Drust, B., Gregson, W. (2014). Applied physiology of emale soccer: an update. Sports Med, 44(9), 1225-40.

Gabbett, T.J. (2010). Development of a Test of Repeated-Sprint Ability for Elite Women's Soccer Players. The Journal of Strength \& Conditioning Research, 24(5), 1191-4.

Haugen, T.H., Tønnessen, E., Hem, E., Leirstein. S., Seiler, S. (2014). VO2max Characteristics of Elite Female Soccer Players, 1989-2007. International Journal of Sports Physiology and Performance, 9(3), 515-21.

Ingebrigtsen, J., Dillern, T., and Shalfawi, SAI. Aerobic capacities and anthropometric characteristics of elite female soccer players. J Strength Cond Res, 25(12).

Jackman, R., Scott, S., Randers, B., Orntoft, C, Blackwell, J., Zar, H., Mohr, M, Krustrup, P. (2013). Musculoskeletal health profile for elite female footballers versus untrained young women before and after 16 weeks of football training. Journal of Sports Sciences 31(13), 1468-74.

Legel, L. \& Gadoury, C. (1989). Validity of $20 \mathrm{~m}$ multi stage fitness test to estimate maximal oxygen uptake. British Journal of Sports Medicine, 22, 141-52.

Likic, S., Bajramovic, I. \& Vranesic-Hadzimehmedovic, D. (2018). Relationship Between Morphological Characteristics and Dynamic Running Parameters in the Case of Boys Aged 10-12 years. J. Anthr. Sport Phys. Educ. (2)1: 27-30.

Krustrup, P., Mohr, M., Ellingsgaard, H., Bangsbo, J. (2005). Physical demands during an elite female soccer game: importance of training status. Medicine Science Sports Exercise. 37, 1242-8.

Magni, M., Krustrup, P., Andersson, H., Kirkendal, D., Bangsbo, J. (2008). The Journal of Strength \& Conditioning Research, 22(2), 341-9.

Manson, S.A., Brughelli, M., and Harris, N.K. (2014). Physiological characteristics of international female soccer players. J Strength Cond Res 28(2), 308-18.

Milanović, Z ${ }_{\mu}$ Sporiš, G, Trajković, N. (2012). Differences in Body Composite and Physical Match Performance in Female Soccer Players According to Team Position. J. Hum. Sport Exerc. 7(1), 67-72.

Mujika, I., Santisteban, J., Impellizzeri, M., Castagna, C. (2009). Fitness determinants success in men's and women's football. Journal of Sports Sciences 27(2), 107-14.

Nikolaidis, P.T. (2014). Weight status and physical fitness in female soccer players: is there an optimal BMI? Sport Sci. Health 10, 41-8.

Nikolaidis, P. T. (2014). Physical Fitness in Female Soccer Players by Player Position: A Focus on Anaerobic Power. Human Movement 15(2), 74-9.

Ozbar, N., Ates, S., Agopyan, A. (2014). The effect of 8-week plyometric training on leg power, jump and sprint performance in female soccer players. J Strength Cond Res, 28(10), 2888-94.

Talović, M., Fiorentini, F., Sporiš, G., Jelešković, E., Ujević, B., Jovanović, M. (2011). Notacijska analiza u nogometu. Sarajevo: Fakultet sporta i tjelesnog odgoja, Univerzitet u Sarajevu.

Trajković, N., Sporiš, G., Milanović, Z., Jovanović, M. (2010). Physical characteristics of elite Serbian female soccer players. Szombathely, Hungary: University of West Hungary, 154-61.

Todd, M. K., Scott, D., \& Chisnall, P. J. (2002). Fitness characteristics of English female soccer players: an analysis by position and playing standard. In Spinks, W., Reilly, T., Murphy, A. (Ed). Science and Football IV (374-381). London: Routledge, Proceedings of the 4th World Congress of Science and Football.

Sporiš, G., Čanaki, M., Barišić, V., (2007). Morphological differences of elite Croatian female soccer players according to team position. Hrvatski športskomedicinski vjesnik, 22(2), 91-6.

Vescovi, J.D. (2012). Sprint speed characteristics of high-level American female soccer players: Female Athletes in Motion (FAiM) study. J Sci Med Sport. 15(5), 474-8

Vukotić, M., Ćorluka, M.,Vasiljević, I., Bubanja, M. (2018). Differences in the Morphological Characteristics and Body Composition of Handball Players WHC Levalea in Montenegro and WHC Grude in Bosnia and Herzegovina (2018). J. Anthr. Sport Phys. Educ. 2(2), 49-53. 